\title{
A POLÍTICA PÚBLICA BRASILEIRA PARA COMUNIDADES QUILOMBOLAS: 0 PROGRAMA BRASIL QUILOMBOLA NO MUNICÍPIO DE CORUMBÁ, NO ESTADO DE MATO GROSSO DO SUL
}

\author{
THE BRAZILIAN PUBLIC POLICY FOR QUILOMBOLAS COMMUNITIES: THE KILOMBOLA BRAZIL PROGRAM IN THE \\ MUNICIPALITY OF CORUMBÁ, IN THE STATE OF MATO GROSSO DO SUL
}

\section{RESUMO}

O trabalho surge na expectativa de analisar os obstáculos enfrentados na implantação do Programa Brasil Quilombola (PBQ) nas Comunidades Quilombolas (CQ) do município de Corumbá-MS. Procura compreender os entraves na implementação dos quatro eixos estabelecidos pela Agenda Social Quilombola (ASQ) - Acesso a Terra; Infraestrutura e Qualidade de Vida; Inclusão Produtiva e Desenvolvimento Local; Direito e Cidadania - por meio do monitoramento e da análise das ações a eles relacionadas, nas três comunidades quilombolas, Campos Correia, Maria Theodora Gonçalves de Paula e Família Ozório. A fim de apreender a realidade vivenciada pelas comunidades quilombolas do município de Corumbá, uma pesquisa a partir de dados secundários e primários foi realizada, através das seguintes intervenções: revisão bibliográfica e levantamento de dados junto aos órgãos públicos, bem como entrevistas nas citadas comunidades. $\mathrm{O}$ desafio proposto é compreender os significados políticos, econômicos e sociais da invisibilidade dessas comunidades, sobretudo suas formas e sinais de resistência, focando principalmente na produção de alternativas de sobrevivência pelos agentes sociais envolvidos, frente à exiguidade do Estado.

Palavras-chave: Políticas Públicas. Comunidades Quilombolas. Resistência.

\section{ABSTRACT}

The work arises in the expectation of analyzing the obstacles faced in the implementation of the Quilombola Brazil Program (PBQ) in the quilombola communities (CQ) in the city of Corumbá - MS. It searches to understand the difficulties in implementing the four axes established by the Quilombola Social Agenda (ASQ) - Access to Land; Infrastructure and Quality of Life; Productive Inclusion and Local Development; Law and Citizenship - by means of monitoring and analyzing the actions related to them in three quilombola communities, Campos Correia, Maria Theodora Gonçalves Paula and Ozório Family. In order to understand the reality experienced by the quilombola communities in the municipality of Corumbá, a survey based on secondary and primary data was carried out through the following interventions: bibliographic review and data collection with public agencies, as well as interviews in the quilombola communities in Corumbá. The challenge put forward is to understand the political, economic and social meanings of these communities' invisibility, especially their forms and signs of resistance, focusing mainly on the production of survival alternatives by the involved social agents against the scarcity of the State.
iD João Batista Alves de Souza ${ }^{a}$

(D) Edvaldo César Moretti ${ }^{\text {b }}$

a Instituto Federal de Mato Grosso do Sul (IFMS), Campo Grande, MS, Brasil

${ }^{\text {b }}$ Universidade Federal da Grande Dourados (UFGD), Dourados, MS, Brasil

DOI: $10.12957 /$ geouerj.2020.40891

Correpondência: daltonmacambira@msn.com

Recebido em: 20 mar. 2019

Revisado em: 7 fev. 2020

Aceito em: 20 mar.2020

Keywords: Public Policies. Quilombola Communities. Resistance. 


\title{
INTRODUÇÃO
}

De acordo com Aníbal Quijano (2005), são evidentes as relações de dominação sobre os africanos e seus descentes na América, onde:

\begin{abstract}
[...] a ideia de raça foi uma maneira de outorgar legitimidade às relações de dominação impostas pela conquista. A posterior constituição da Europa como nova id-entidade depois da América e a expansão do colonialismo europeu ao resto do mundo conduziram à elaboração da perspectiva eurocêntrica do conhecimento e com ela à elaboração teórica da ideia de raça como naturalização dessas relações coloniais de dominação entre europeus e não-europeus. Historicamente, isso significou uma nova maneira de legitimar as já antigas idéias e práticas de relações de superioridade/inferioridade entre dominantes e dominados. (QUIJANO, 2005 p.118)
\end{abstract}

Diante do contexto histórico apresentado, percebemos que, além do racismo, a população negra e as comunidades quilombolas convivem com o descaso do Estado no que diz respeito ao acesso à cidadania e às políticas públicas que buscam diminuir a desigualdade social existente. Como uma entidade complexa, para Jaime Osorio (2014), o Estado representa "essencialmente dominação de classes", "condensação das relações de poder" e, ainda, "violência concentrada". Nesse sentido, em lugar de buscar a solução dos problemas enfrentados pelas comunidades quilombolas, ele se apresenta como uma "nova problemática" para elas, seja na demora da regularização de seus territórios, seja na falta de investimento de recursos públicos em infraestrutura e qualidade de vida, ou na ausência dos direitos à cidadania.

Embora não tenhamos a pretensão de produzir uma análise profunda e conceitual de território neste trabalho, focado basicamente em elucidar o processo de resistência das comunidades quilombolas em busca do reconhecimento do seu território, é possível constatar que o conceito de território é apropriado por políticas públicas governamentais e acaba sendo usado de maneira descontextualizada. Ao analisarmos o Programa Brasil Quilombola enquanto política pública, verificamos que as comunidades quilombolas podem ser classificadas como demandas recorrentes, caracterizadas por Rua (1998) como aquelas que expressam problemas não resolvidos ou mal resolvidos e voltam sempre a aparecer no debate político e na agenda governamental.

\section{As políticas públicas}

Na obra Formulação de Políticas Públicas, Ana Cláudia Niedhardt Capella (2018), esclarece que no processo de formulação de políticas públicas sempre envolverá dois elementos principais, sendo o primeiro a definição de uma agenda, em seguida a definição de alternativas. Na visão da autora a definição da agenda irá atender problemas específicos de um grupo de atores, enquanto a definição das alternativas irá envolver um layout de um plano de ação a ser desenvolvido. Capella (2018) também discorre sobre os ciclos das políticas públicas: 
Nos estudos sobre políticas públicas, é muito comum que a formulação seja apresentada no contexto do ciclo de políticas, sendo nesse caso identificada como etapa inicial, à qual se seguem, geralmente, as fases de tomada de decisão, implementação e avaliação. Assim, a formulação pode ser caracterizada como uma etapa pré-decisória, ou seja, anterior a qualquer atividade de formalização de uma política, envolvendo fundamentalmente a identificação de problemas que requerem atenção governamental (definição da agenda) e uma busca inicial por soluções possíveis, confrontadas com seus custos e efeitos estimados (definição de alternativas). Quando compreendida por meio da metáfora do ciclo, a fase de formulação assume grande relevância, uma vez que essa etapa inicial tem impacto sobre todo o processo de produção de políticas que se desenvolve posteriormente. (CAPELLA, 2018, p. 9)

No caso da criação Programa Brasil Quilombola enquanto política pública, é necessário uma análise da metáfora do ciclo das políticas públicas, apontada por Capella (2018), sendo que a tomada de decisão, nesse caso foi um tanto tardia, ou seja, mais de um século após a abolição da escravidão no Brasil, durante esse período as comunidades quilombolas estiveram ausente da agenda governamental.

Para Maria das Graças Rua (2009), as políticas públicas (policies) são resultantes das atividades políticas (politics), compreendendo, portanto, um conjunto de decisões e ações relativas à alocação imperativa de valores.

\begin{abstract}
Uma política pública geralmente envolve mais do que uma decisão e requer diversas ações estrategicamente selecionadas para implementar as decisões tomadas. Já uma decisão política corresponde a uma escolha dentre um leque de alternativas, conforme a hierarquia das preferências dos atores envolvidos, expressando - em maior ou menor grau - uma certa adequação entre os fins pretendidos e os meios disponíveis. Assim, embora uma política pública implique decisão política, nem toda decisão política chega a constituir uma política pública. (RUA, 2009, p.1)
\end{abstract}

Em relação aos autores envolvidos, sabemos que não há representatividade política das comunidades quilombolas no Congresso Nacional, onde há forte representatividade da bancada ruralista ${ }^{1}$, assim a maioria das decisões políticas não irão atender as políticas públicas de determinadas demandas, no caso das comunidades quilombolas os direitos adquiridos ainda correm sérios riscos, um exemplo é o caso do Partido Democrata (DEM) entrou com uma Ação Direta de Inconstitucionalidade (ADI) no STF, questionando o decreto 4887/2003 que regulamenta a titulação das terras dos quilombos, essa ação se arrastou por quase 14 anos no STF. Nesse contexto corroboramos com a autora no que diz respeito as decisões que são tomadas desde a criação de uma política pública até a sua execução, esse ciclo necessita de várias articulações estratégicas, seja entre ministérios, secretarias de estado e municípios envolvidos.

De acordo com Celina Souza (2006), as políticas públicas repercutem na economia e nas sociedades, daí por que qualquer teoria da política pública precisa também explicar as inter-relações entre Estado, política, economia e sociedade. Para a autora:

1 De acordo com o cientista político David Fleischer, da Universidade de Brasília, a bancada ruralista pode ser denominada como Grupo Temporário Público de Interesse Particular, por ser um conjunto suprapartidário de atores públicos eletivos. 
O processo de definição de políticas públicas, sociedades e Estados complexos como os constituídos no mundo moderno estão mais próximos da perspectiva teórica daqueles que defendem que existe uma "autonomia relativa do Estado", o que faz com que o mesmo tenha um espaço próprio de atuação, embora permeável a influências externas e internas. (SOUZA, 2006, p.27)

A autora acrescenta ainda que a "autonomia" do Estado e o desenvolvimento das "capacidades" na implantação das políticas públicas dependem de vários fatores presentes em diferentes momentos históricos de cada país. No Brasil, esse contexto pode ser apresentado de maneira bem objetiva: basta comparar a implementação do Programa Brasil Quilombola (PBQ) nos governos progressistas de Lula e Dilma e seu declínio no governo Temer, sob o qual a maioria dos processos de certificação dos territórios quilombolas foram paralisados. Isso reflete as limitações que o Estado enfrenta na execução de várias ações previstas no Programa, principalmente a concernente ao acesso à terra pelas comunidades quilombolas, visto haver forte embate político promovido pela bancada ruralista contra o reconhecimento dos territórios a elas destinados.

\section{A implementação do Programa Brasil Quilombola}

Mais de um século depois de vigência da Lei Imperial no 3.353, de 13 de maio de 1888, a Lei Áurea, foi lançado, em 12 de março de 2004, no primeiro mandato do Governo Lula, o Programa Brasil Quilombola (PBQ). Regulamentado por meio do Decreto no 6.261, de novembro de 2007, tinha como objetivo consolidar os marcos da política de Estado para as áreas quilombolas. No entanto, muitas comunidades quilombolas não foram atendidas pelo programa, entre elas as do município de Corumbá - MS, que lutam há mais de uma década pelo reconhecimento do seu território.

O Programa Brasil Quilombola², cuja implementação envolveu mais de 20 órgãos do governo federal, dentre os quais se destacam INCRA, IBAMA, Delegacias Regionais do Trabalho, Funasa, Caixa Econômica Federal, Ministério da Cultura e Ministério do Planejamento Social, tem apresentado, porém, resultados longe do esperado.

Em consonância à oposição policies e politics proposta por Rua (2009) está o fato de que as comunidades quilombolas não contam com representatividade política no Congresso Nacional, ao contrário de outros segmentos, como por exemplo, os ruralistas ${ }^{3}$. É certo, portanto, que a maioria das decisões políticas não visa a atender políticas públicas de determinadas demandas, como é o caso das comunidades quilombolas, que têm até os direitos adquiridos sob sérios riscos. Uma Ação Direta de Inconstitucionalidade (ADI), que se

2 O Programa Brasil Quilombola foi lançado em 12 de março de 2004, com o objetivo de consolidar os marcos da política de Estado para as áreas quilombolas. Ver mais em http://www.seppir.gov.br

3 De acordo com o cientista político David Fleischer, da Universidade de Brasília, a bancada ruralista pode ser denominada como Grupo Temporário Público de Interesse Particular, por ser um conjunto suprapartidário de atores públicos eletivos. 
arrastou por quase 14 anos, foi apresentada ao STF pelo Partido Democrata (DEM), questionando o Decreto no $4.887 / 2003$, que regulamenta a titulação das terras dos quilombos.

Em relação à classe política, numa breve análise do Estado como questão política, Jaime Osorio (2014) pondera:

Se considerarmos as pessoas que atuam na cena política, podemos afirmar que a classe política é mais ampla que a classe reinante, pois, além dos funcionários que ocupam as altas esferas do aparato do Estado, a classe política engloba os altos quadros dos partidos políticos, dos sindicatos e das corporações empresariais, o alto clero que participa da política, diretores de jornais, editoriais e formadores da opinião pública em geral. (OSORIO, 2014, p.56-57)

Além da classe composta pelo corpo de funcionários do aparato de Estado presidente, ministros, altos comandos militares e à classe política partidos políticos, empresários, sindicatos e setores da mídia apresentadas por Osorio (2014), acrescentamos aqui uma terceira classe, a dos excluídos, na qual estão inseridas as comunidades quilombolas. Essa classe permanece dependendo das articulações políticas e das decisões de governo para a implementação de políticas públicas.

\section{Área de estudo}

A presente pesquisa procura analisar os entraves na implantação do Programa Brasil Quilombola (PBQ) no município de Corumbá - MS, que concentra a maior população parda e preta do estado de Mato Grosso do Sul, de acordo com dados do IBGE (2010), (Quadro 1), região que nos revela a beleza natural do Pantanal, além de abrigar a riqueza cultural da fronteira entre Brasil e Bolívia, onde se encontram três das vinte e duas comunidades quilombolas existentes no estado.

Quadro 1. População e Etnias de Corumbá - MS. Fonte: IBGE/ Elaborado pelo autor.

\begin{tabular}{cccccc}
\hline População & Amarela & Branca & Indígena & Parda & Preta \\
\hline$\%$ & $1,17 \%$ & $28,83 \%$ & $0,38 \%$ & $\mathbf{6 2 , 6 0 \%}$ & $\mathbf{7 , 0 2 \%}$ \\
Habitantes & 1.209 & 29.895 & 398 & $\mathbf{6 4 . 9 2 3}$ & $\mathbf{7 . 2 7 8}$ \\
\hline
\end{tabular}

De acordo com o Atlas Observatório Quilombola ${ }^{4}$, a situação das comunidades quilombolas de Corumbá (Figura 1), no que respeita à expedição de sua certidão de autodefinição $0^{5}$ é a seguinte: a Comunidade Família Ozório a obteve em 6 e janeiro de 2010; a certidão da Comunidade Família Maria Theodora Gonçalves de

4 Ver mais em: $\underline{\text { http://koinonia.org.br/atlasquilombola }}$

5 A Fundação Cultural Palmares realiza a emissão da certidão de autodefinição como remanescente de quilombo. Ver mais em: DECRETO No 4.887, DE 20 DE NOVEMBRO DE 2003. 
Paula, foi publicada no Diário Oficial da União em 22 de dezembro de 2011; enquanto a da comunidade Negra Quilombola Campos Correia só foi publicada no dia 01de abril de 2013.

Figura 1. Mapa de localização das comunidades quilombolas no município de Corumbá - MS. Elaborado pelo autor.

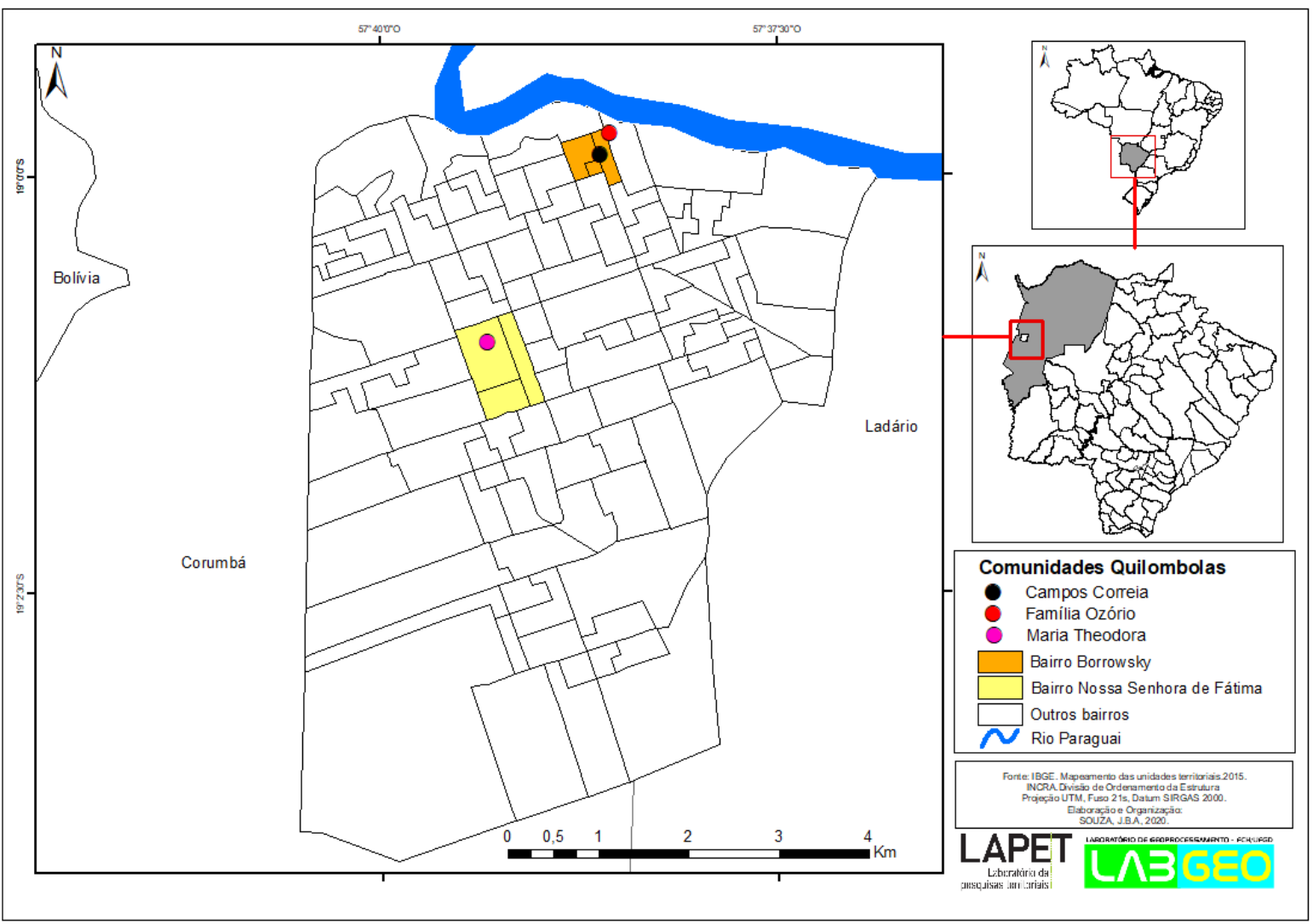

Segundo Rua (2009), quando uma política envolve os diferentes níveis de governo federal, estadual, municipal e diferentes regiões de um mesmo país, ou ainda, diferentes setores de atividade, sua implementação pode se mostrar uma questão problemática, já que o controle do processo se torna mais complexo.

No município de Corumbá, ainda que as três citadas comunidades quilombolas encontrem-se em processo de titulação dos seus territórios, a complexidade apontada pela autora está presente, visto haver posições contraditórias entre o poder público, ONGs e pesquisadores.

Um levantamento realizado pela Fundação Cultural Palmares (FCP) em 2011, indica a existência de oito comunidades quilombolas em Corumbá, sendo seis na área urbana - Comunidade Negra Família Campos e Correia; Comunidade Negra Família Rodrigues; Comunidade Negra Família Silva; Comunidade Negra Beira Rio - Família Delgado e Comunidade Negra do Bairro Maria Leite - Família Cezária dos Santos - e duas na zona rural - a Comunidade Colônia São Domingos e a Comunidade Cabeceira Preta. No entanto apenas três 
comunidades possuem o certificado de autodefinição expedido pela fundação Palmares são elas: Comunidade Campos Correia, Comunidade Ribeirinha Família Ozório e Comunidade Maria Theodora, conforme figura 1.

De acordo com dados da extinta Secretaria de Estado de Trabalho e Assistência Social de Mato Grosso do Sul (SETAS), no relatório intitulado Política Estadual de Assistência Social de Mato Grosso do Sul (2013), são citadas dez comunidades quilombolas no município de Corumbá: Comunidade Colônia São Domingos; Comunidade Negra Beira Rio - Família Delgado; Comunidade Negra do Bairro Maria Leite; Família Cezária dos Santos; Comunidade Negra Família Leite Pereira; Comunidade Negra Família Rodrigues; Comunidade Negra Família Magalhães Vieira; Comunidade Negra Quilombola Campos Correia; Família Ozório; Comunidade Família Maria Theodora Gonçalves de Paula. Flávio dos Santos Gomes, por sua vez, na obra “Mocambos e Quilombos: Uma história do campesinato negro no Brasil", publicada em 2015, revela que o município de Corumbá possui onze comunidades quilombolas.

O Instituto Nacional de Colonização e Reforma Agrária (INCRA) realiza trabalhos técnicos em duas comunidades, sendo que na comunidade Família Ozório, foi finalizado o Relatório Técnico de Identificação e Delimitação (RTID) e na comunidade Campos Correia a pedido do Ministério Público Federal foi aberto Processo Administrativo de Regularização Fundiária.

Segundo a presidenta ${ }^{6}$ do Instituto da Mulher Negra do Pantanal (IMENEGRA), a imprecisão de dados em relação à quantidade de comunidades quilombolas no município de Corumbá ocorre por dois fatores: primeiro, porque o mapeamento realizado por Organizações não Governamentais (ONGs) classificou várias comunidades negras como quilombolas, apesar de não se caracterizarem como tal.

No começo não tinha os números exatos da quantidade de comunidades quilombolas em Corumbá, nós realizamos um trabalho árduo. Na verdade, nem sabiam se havia quilombolas aqui (...) depois vieram as ONGs pesquisar os quilombos e começou aumentar significativamente essas comunidades (...) Mas na realidade são três com os documentos legalizados. O movimento negro através do IMNEGRA fez essa busca e auxiliou desde a criação das associações (Ednir de Paulo, 12/2017)

Em segundo lugar porque, em trabalho realizado em 2013, o poder público estadual, através da extinta Secretaria de Trabalho e Assistência Social do Mato Grosso do Sul (SETAS) ${ }^{7}$, elaborou um relatório referente às comunidades quilombolas no estado sem realizar uma pesquisa empírica e detalhada, do que resultaram dados inconsistentes.

6 Entrevista realizada no dia 14/12/2017 com a presidenta do Instituto da Mulher Negra do Pantanal IMNEGRA Ednir de Paulo.

7 A partir de 2015, a SETAS foi substituída pela Secretaria de Estado de Direitos Humanos, Assistência Social e Trabalho (SEDHAST) Ver mais em: http://www.sedhast.ms.gov.br/ 
Analisar a questão quilombola no Mato Grosso do Sul requer um olhar crítico sobre o papel do Estado. Osório (2014), que discute suas particularidades, afirma que.

\begin{abstract}
O Estado é a única instituição que tem a capacidade de fazer com que interesses sociais particulares possam parecer como interesse de toda a sociedade. Esta tarefa não pode ser realizada por instituições tão importantes na organização societária moderna como as igrejas, os meios de comunicação, as corporações empresariais, os partidos políticos, os sindicatos ou outra qualquer, que senão o Estado. (OSORIO, 2014, p.18)
\end{abstract}

O autor salienta que somente o Estado está habilitado a atender os interesses sociais de determinados segmentos da sociedade e, ao mesmo tempo, passar a ideia de que esses benefícios atingem a sociedade de modo geral. Mas isso não ocorre em relação às comunidades quilombolas, pois os interesses sociais dessa pequena parte da sociedade se antagonizam com os interesses de outra parcela, composta pelos grandes proprietários fundiários. Consequentemente, enquanto o Estado não oferece condições mínimas para atender as necessidades das comunidades quilombolas, mantendo inconclusivo o processo de certificação do território, inúmeras famílias não têm acesso à terra, sofrem por falta de infraestrutura, desenvolvimento local, qualidade de vida, enfim, por ausência de direitos e cidadania.

As ações e monitoramento dos quatro eixos da Agenda Social Quilombola

Por meio do Decreto no 6.261/2007, a Agenda Social Quilombola (ASQ), desenvolvida no âmbito do Programa Brasil Quilombola (PBQ), tem suas ações agrupadas em quatro eixos principais: Acesso à terra; Infraestrutura e qualidade de vida; Inclusão produtiva e desenvolvimento local; Direitos e cidadania.

De acordo com documento do Ministério dos Direitos Humanos, o Eixo 1-Acesso à terra - compreende:

Execução e acompanhamento dos trâmites necessários para a regularização fundiária das áreas de quilombo, que constituem título coletivo de posse das terras tradicionalmente ocupadas. O processo se inicia com a certificação das comunidades e se encerra na titulação, que é a base para a implementação de alternativas de desenvolvimento para as comunidades, além de garantir a sua reprodução física, social e cultural; (PBQ, 2013, p.18)

O acesso à terra é um dos principais entraves enfrentados pelas comunidades quilombolas no Brasil: mais de uma década após a criação do PBQ, apenas 2.422 registros foram oficializados em todo país, de acordo com dados divulgados pelo Sistema de Diagnóstico e Monitoramento de Políticas Estratégicas para a Promoção da Igualdade Racial no Brasil. O monitoramento apresenta o mapeamento das comunidades quilombolas no país e, entre inúmeras informações, revela que a maior concentração de comunidades quilombolas reconhecidas oficialmente pelo Estado está localizada nos estados: Bahia (614), Maranhão (477), Minas Gerais (222) e Pará (214) (Gráfico 1). De acordo com o Painel de Monitoramento PBQ, no Distrito Federal e nos estados Acre e Roraima, não há nenhuma comunidade quilombola certificada. 
Gráfico 1. Estados com maior concentração de comunidades quilombolas no Brasil. Fonte: INCRA e Fundação Cultural Palmares Elaborado pelo autor.

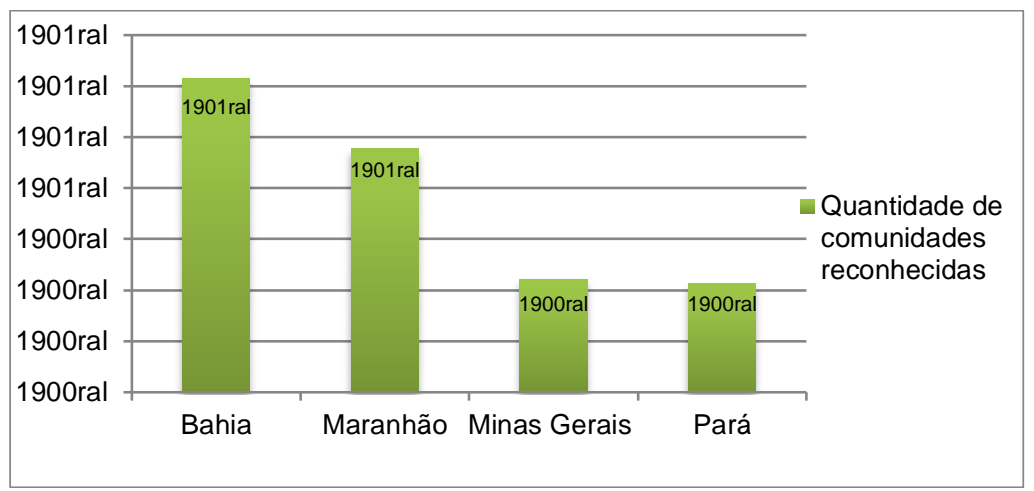

De acordo com dados do INCRA e da Fundação Cultural Palmares, organizados pelo Comitê de Gestão da Agenda Social Quilombola (CGASQ), apenas 22 comunidades foram certificadas no Mato Grosso do Sul em 2014 (Quadro 1). As comunidades que pretendem obter a regularização de seu território precisam seguir estas sete etapas: na fase inicial, ocorre a abertura do processo no INCRA para o reconhecimento do território quilombola; em seguida, tem início o estudo da área para a elaboração do Relatório Técnico de Identificação e Delimitação (RTID); após a publicação do RTID, o processo é aberto para análise e julgamento de recursos; na sequência, a portaria de reconhecimento é publicada no D.O.U, declarando os limites do território; feito isso, um decreto presidencial autoriza a desapropriação das terras; o penúltimo passo é a retirada dos ocupantes; enfim, é emitido título de propriedade coletiva para a comunidade.

Segundo o monitoramento do $\mathrm{PBQ}$, apenas duas comunidades foram tituladas, e outras duas encontram-se na fase de elaboração do Relatório Técnico de Identificação e Delimitação.

Quadro 1. Situação das Comunidades Quilombolas no Mato Grosso do Sul. Fonte: INCRA e FCP. Elaborado pelo autor.

\begin{tabular}{|c|l|l|l|}
\hline Quantidade & Comunidade & Munícipio & Situação \\
\hline 1 & Chácara do Buriti & Campo Grande & Decreto \\
\hline 2 & Colônia de São Miguel & Maracaju & Decreto \\
\hline 3 & Furnas do Dionísio & Jaraguari & Decreto \\
\hline 4 & Furnas da Boa Sorte & Corguinho & Decreto \\
\hline 5 & Dezidério Felipe de Oliveira/Picadinha & Dourados & RTID \\
\hline 6 & Família Cardoso & Nioaque & RTID \\
\hline 7 & $\begin{array}{l}\text { Comunidade Ribeirinha Família Ozório / Ilha do } \\
\text { Pescador* }\end{array}$ & Corumbá & Certificada \\
\hline 8 & $\begin{array}{l}\text { Comunidade Ribeirinha Quilombola Família } \\
\text { Campos Correia* }\end{array}$ & Corumbá & Certificada \\
\hline 9 & $\begin{array}{l}\text { Comunidade Família Maria Theodora Gonçalves de } \\
\text { Paula* }\end{array}$ & Corumbá & Certificada \\
\hline 10 & São João Batista & Campo Grande & Certificada \\
\hline 11 & Eva Maria De Jesus Tia Eva (Vila São Benedito) & Campo Grande & Certificada \\
\hline 12 & Santa Tereza/ Família Malaquias & Figueirão & Certificada \\
\hline 13 & Família Araújo e Ribeiro & Nioaque & Certificada \\
\hline 14 & Furnas dos Baianos & Aquidauana & Certificada \\
\hline 15 & Águas do Miranda & Bonito & Certificada \\
\hline 16 & Ribeirinha Família Bulhões & Nioaque & Certificada \\
\hline
\end{tabular}




\begin{tabular}{|c|l|l|l|}
\hline 17 & Ribeirinhos Família Romano Martins da Conceição & Nioaque & Certificada \\
\hline 18 & Família Quintino & Pedro Gomes & Certificada \\
\hline 19 & Família Jarcem & Rio Brilhante & Certificada \\
\hline 20 & Ourolândia & Rio Negro & Certificada \\
\hline 21 & Família Bispo & Sonora & Certificada \\
\hline 22 & Comunidade dos Pretos & Terenos & Certificada \\
\hline * Comunidades pesquisadas & \multicolumn{2}{|l}{} \\
\hline
\end{tabular}

Das 22 comunidades quilombolas reconhecidas no estado do Mato Grosso do Sul, três delas estão localizadas no município de Corumbá. Entre elas, a Família Ozório ${ }^{8}$, estabelecida às margens do Rio Paraguai. As 12 famílias que a compõem dependem exclusivamente do trabalho informal, ligado à pesca e à agricultura familiar. Além de se dedicar ao cultivo de frutas e legumes, a comunidade possui uma das maiores hortas do município (Figura 2). No entanto, passa por inúmeras dificuldades, tais como: falta de espaço para o cultivo da lavoura e de assistência técnica especializada, ausência de maquinário agrícola e de infraestrutura para o escoamento da produção. As famílias ocupam um pequeno espaço territorial disputado por uma olaria, uma área do Exército e propriedades particulares. Ali, a questão das relações de produção das comunidades quilombolas corumbaenses é evidente, pois, enquanto aguardam o processo de titulação do território, os moradores buscam alternativas de sobrevivência e resistência.

Figura 2. Horta e cultivo de frutas na Comunidade Quilombola Família Ozório. Fonte: SOUZA. J.B.A; 2017

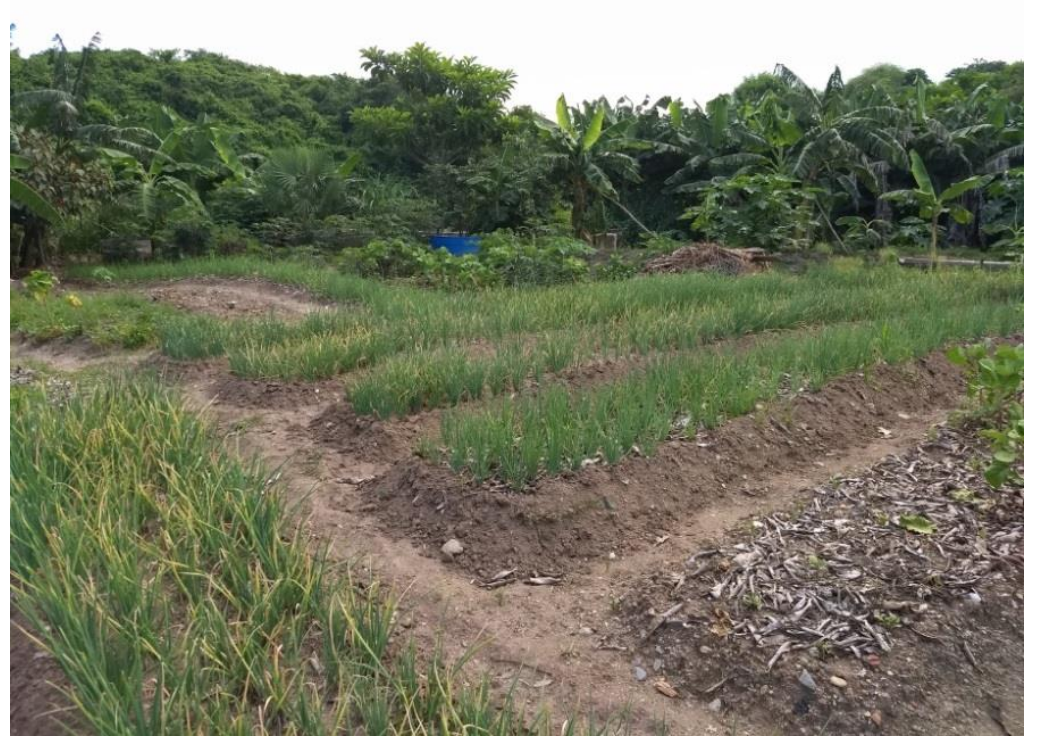

8 O patriarca da família, senhor Miguel Ozório, trabalhou grande período de sua vida em fazendas do Pantanal. Após a enchente do rio Paraguai, na década de 1980, a família ocupou uma área à margem do rio e até hoje luta pela posse da terra. 
De acordo com um dos membros da família Ozório ${ }^{9}$, responsável pela produção da horta da comunidade, a venda das hortaliças para os feirantes bolivianos é a única alternativa possível no momento:

Vendemos mais barato, lá na feira, "eles" vendem pelo dobro ou mais, mas essa é a única saída para vender o que é produzido aqui (...) Não temos um espaço na feira (Banca), isso é complicado, a associação não tem poder para isso, os bolivianos dominam essa questão da feira (...) também não temos como transportar, fica mais fácil porque eles vêm buscar aqui (...) as verduras é do quilombo, $e$ todos pensam que é plantada pelos bolivianos. (Jorge Ozório 11/12/2017)

Como aponta Poulantzas (1980), as relações de produção traduzem-se na forma de poderes de classe, organicamente articulados às relações políticas e ideológicas que os consagram e legitimam. Essa articulação pode ser equiparada ao domínio exercido pelos bolivianos na feira local e à ausência dos quilombolas nesse espaço, bem como às relações políticas que envolvem os dois grupos.

O Eixo 2 da Agenda Social Quilombola presente no PBQ - Infraestrutura e qualidade de vida prevê a:

Consolidação de mecanismos efetivos para destinação de obras de infraestrutura (habitação, saneamento, eletrificação, comunicação e vias de acesso) e construção de equipamentos sociais destinados a atender as demandas, notadamente as de saúde, educação e assistência social; ( $P B Q$ 2013, p.20)

A partir dos dados do Painel de Monitoramento do PBQ, porém, é possível verificar que tal meta está longe de ser completamente atingida: no total, foram contratadas 5.646 unidades no Programa Minha Casa Minha Vida, e apenas 34\% dos domicílios têm acesso a água potável através da rede de distribuição, somando 26.690 domicílios. A inclusão das famílias quilombolas de baixa renda no Cadúnico ${ }^{10}$, ou seja, aquelas que recebem até meio salário mínimo per capita, ou somam até três salários mínimos de renda mensal total, possibilita-Ihes o acesso a diversos programas e benefícios sociais do governo federal, entre eles: Programa Bolsa Família; Programa Minha Casa Minha Vida; Programa de Cisternas; Programa de Fomento às Atividades Produtivas Rurais; Programa Brasil Carinhoso; Telefone Popular; Tarifa Social de Energia Elétrica; além de isenção de taxas em concursos públicos.

No Mato Grosso do Sul, 441 famílias estão cadastradas no CadÚnico. Todavia, em relação às famílias quilombolas de Corumbá não há dados disponíveis, visto estarem os territórios quilombolas ainda em fase de reconhecimento nesse município. No que concerne às características dos domicílios das comunidades quilombolas no Mato Grosso do Sul, o monitoramento do PBQ apresenta os seguintes dados: 291 famílias têm acesso à rede geral de distribuição de água, totalizando $67,1 \%$ da população quilombola; 40 famílias apenas,

9 Entrevista realizada com o responsável pela horta, Sr. Jorge Ozório, em 11/12/2017.

10 O Cadastro Único - CadÚnico - é um conjunto de informações sobre as famílias brasileiras em situação de pobreza e extrema pobreza, utilizado pelo governo federal, pelos estados e municípios para implementação de políticas públicas capazes de promover melhoria da qualidade de vida. Ver mais em: http://www.caixa.gov.br/cadastros/cadastro$\underline{\text { unico/Paginas/default.aspx }}$ 
ou $9,5 \%$, são atendidas com a rede coletora de esgoto, enquanto 274 , o que corresponde a 90,5\%, ainda utilizam a fossa rudimentar; a coleta de lixo atende 260 famílias, correspondendo a 59\% (Gráfico 2).

Gráfico 2. Infraestrutura e Qualidade de Vida das Comunidades Quilombolas no Mato Grosso do Sul. Fonte: INCRA e Fundação Cultural Palmares Elaborado pelo autor.

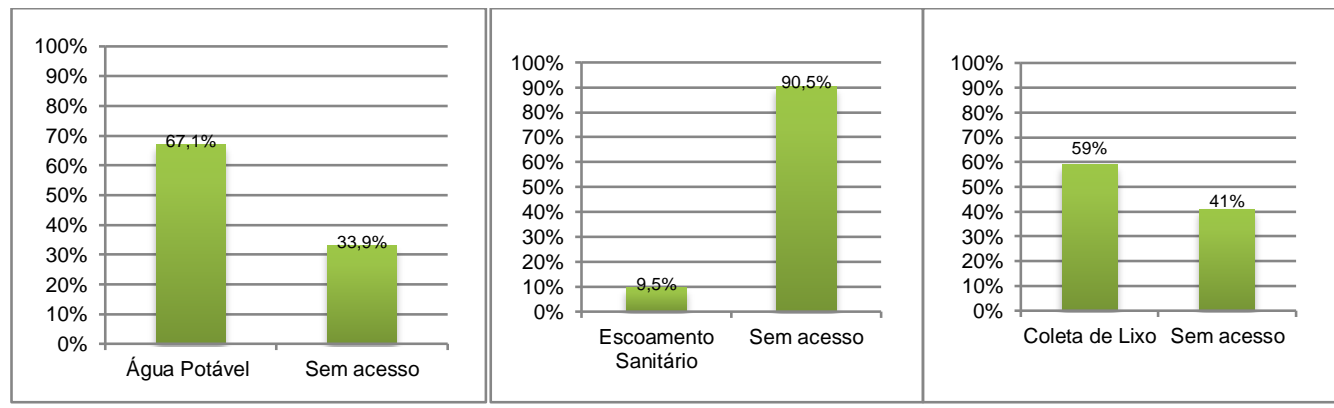

A eletrificação nas comunidades quilombolas no Mato Grosso do Sul chega a 96,4\% das famílias com acesso a energia elétrica no estado, por outro lado apenas 5,4\% têm acesso à Tarifa Social, de acordo com os dados apresentados pelo Painel de Monitoramento do PBQ publicado no segundo semestre de 2014.

A realidade vivida pelas comunidades quilombolas do município de Corumbá demonstra, portanto, que o Eixo 2 da Agenda Social Quilombola - Infraestrutura e qualidade de vida - está aquém do que propõe o Programa Brasil Quilombola. De acordo com o Boletim de Serviços ${ }^{11}$ publicado em 19 de fevereiro de 2014, na página do Ministério Público Federal-MS, a Comunidade Quilombola Família Campos Correia, uma das três existentes no município de Corumbá, enfrenta situação de precariedade, com a ausência de serviços básicos essenciais, como energia elétrica, água potável ou coleta de lixo. Em março de 2014, o Ministério Público Federal oficiou a prefeitura municipal de Corumbá, a Empresa Energética de Mato Grosso do Sul - ENERSUL e a Empresa de Saneamento de Mato Grosso do Sul - SANESUL, concedendo-Ihes uma prazo para regularizar a oferta de serviços àquela comunidade.

O quadro se agravou ainda mais após a construção de um muro (Figura 3), que impede o acesso dos moradores da comunidade à Rua Geraldino Martins de Barros, fazendo com que as providências referentes ao direito a energia elétrica, água potável e coleta de lixo ficassem restritas aos ofícios encaminhados pelo MPF, enquanto as famílias residentes em seu entorno continuam vivendo em situação de vulnerabilidade socioambiental.

11 Ver mais em: http://www.mpf.mp.br/ms/sala-de-imprensa/noticias-ms/mpf-ms-em-corumba-comunidade-quilombolasofre-com-falta-de-acesso-a-servicos-basicos 
Figura 3. Muro que impede o acesso a Comunidade Quilombola Campos Correia. Fonte: SOUZA. J.B.A; 2017

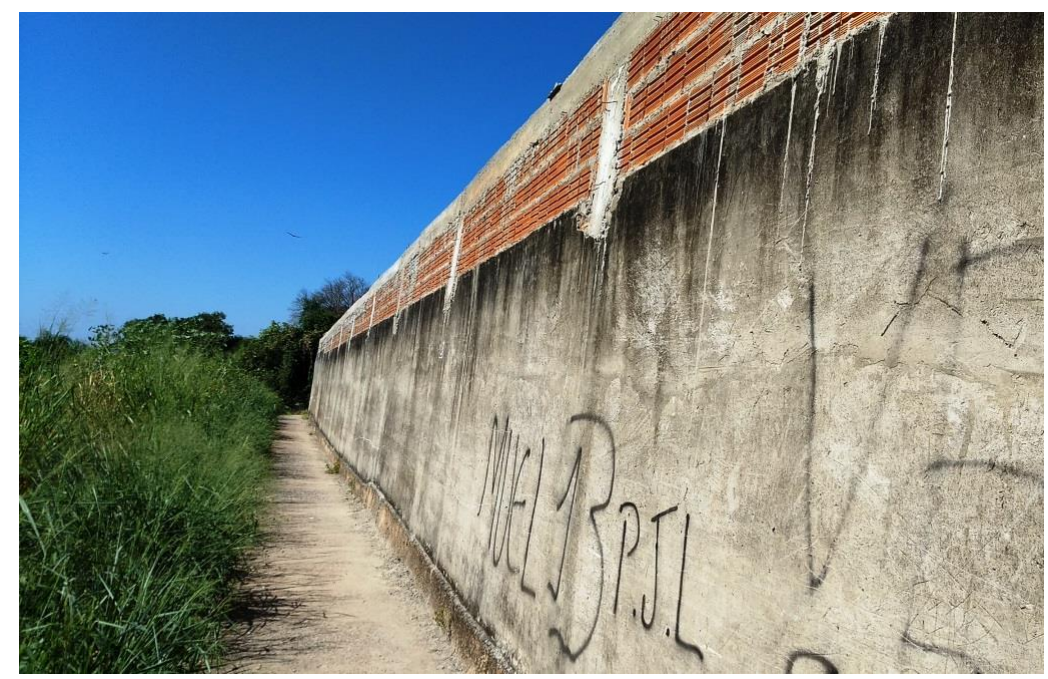

Os dados referentes à Tarifa Social e à inserção das famílias da Comunidade Campos Correia no CadÚnico ainda não estão disponíveis no Painel de Monitoramento do Programa Brasil Quilombola. Durante a pesquisa de campo, constatamos que algumas famílias não estavam recebendo o benefício do Bolsa Família nem o Auxílio Pesca. Ambas as questões, o isolamento da comunidade após a construção do muro e a suspenção dos benefícios dos programas sociais, foram encaminhadas ao Ministério Público Federal.

O Eixo 3 da Agenda Social Quilombola - Inclusão produtiva e desenvolvimento local - representa um dos aspectos mais importantes no processo de resistência das comunidades quilombolas brasileiras, pois enfatiza

O apoio ao desenvolvimento produtivo local e autonomia econômica, baseado na identidade cultural e nos recursos naturais presentes no território, visando à sustentabilidade ambiental, social, cultural, econômica e política das comunidades; (PBQ, 2013, p.30)

Vinculando o desenvolvimento produtivo e a autonomia econômica aos recursos existentes na comunidade, tal proposta foca obrigatoriamente na questão do território. De acordo com Marcos Saquet (2015), o território é diferenciado por Raffestin e Bresso, especialmente a partir da territorialidade cotidiana, ou seja, do conjunto de relações estabelecidas na vida em sociedade, mediada pelo trabalho, pelo poder e pela linguagem. Para o autor, três aspectos evidenciam a diferença entre espaço e território:

a) as relações de poder numa compreensão pluridimensional, constituindo campos econômicos, políticos e culturais; b) a construção histórica e relacional das identidades; c) o movimento de territorialização, desterritorialização e reterritorialização (TDR). (SAQUET, 2015, p.39)

Partimos da concepção de que a definição dos territórios quilombolas, ação inserida na política do governo federal, está diretamente relacionada aos aspectos apontados por Saquet (2015), conforme se observa o que dispõe o Artigo 2 ㅇ do Decreto 4.887/2003: 
Consideram-se remanescentes das comunidades dos quilombos, para os fins deste Decreto, os grupos étnico-raciais, segundo critérios de auto-atribuição, com trajetória histórica própria, dotados de relações territoriais específicas, com presunção de ancestralidade negra relacionada com a resistência à opressão histórica sofrida. (BRASIL, 2003)

Visto que a caracterização dos remanescentes das comunidades dos quilombos é atestada por autodefinição da própria comunidade, bem como a demarcação de suas terras leva em consideração critérios de territorialidade por ela apontados, podemos considerar aqui a presença do segundo aspecto apresentado por Saquet (2015), que diz respeito à construção histórica e relacional das identidades.

É importante salientar a ressemantização do conceito quilombo, em que o termo "remanescente" foi amplamente debatido pela Associação Brasileira de Antropologia (ABA). Referente a essa ressemantização Arruti (2008), esclarece que não é possível falar dos quilombos sem adjetivá-los, seja por meio da fórmula legal que lança mão de "remanescentes", ou das tentativas de ajuste desta, por meio de "contemporâneos", corroboramos com o autor, pois entendemos que ao adjetivar o quilombo como remanescente ele pode ser compreendido como o que "resta", quando na realidade os quilombos resistiram ao logo das décadas e se tornaram quilombos contemporâneos.

Na sociedade contemporânea, as comunidades quilombolas passaram a representar não apenas os remanescentes de quilombos, mas também resistência e a existência de seus costumes, tradições, num processo de resistência que ocorre o movimento de territorialização, desterritorialização e reterritorialização (TDR) das comunidades quilombolas.

No que diz respeito especificamente à parte prática da proposta do Eixo 3 - Inclusão produtiva e desenvolvimento local, porém, são imperceptíveis as ações executadas nas comunidades quilombolas de Corumbá. Acompanhando a realidade do país, em que a proporção de trabalhadores quilombolas envolvidos com atividades extrativistas atinge mais de $73 \%$ no território nacional, no Mato Grosso do Sul esse percentual chega a 23,3\%. Em fevereiro de 2013, a Agência de Desenvolvimento Agrário e Extensão Rural de Mato Grosso do Sul - AGRAER realizou a entrega de três mil quilos de sementes de feijão, milho e hortaliças para 14 comunidades quilombolas do estado. No município de Corumbá, somente uma comunidade recebeu esse benefício e, ainda assim, a distribuição das sementes não ocorreu de maneira contínua. Nenhuma das comunidades quilombolas de Corumbá foi inserida, igualmente, nas ações implementadas pela Subsecretaria de Políticas para Promoção da Igualdade Racial e Cidadania - SUBPIRC, na Rota do Desenvolvimento, para divulgar a culinária e o artesanato das comunidades indígenas e quilombolas. 
O quarto e último eixo da Agenda Social Quilombola - Direitos e cidadania - está pautado na participação e no envolvimento das comunidades quilombolas no que respeita a reivindicação e garantia de direitos, quando propõe o:

Fomento de iniciativas de garantia de direitos promovidas por diferentes órgãos públicos e organizações da sociedade civil, estimulando a participação ativa dos representantes quilombolas nos espaços coletivos de controle e participação social, como os conselhos e fóruns locais e nacionais de políticas públicas. (PBQ, 2013, p.42)

De acordo com o diagnóstico da Secretaria de Políticas de Promoção da Igualdade Racial da Presidência da República (2012), as intervenções estatais dentro desse eixo têm como objetivo promover o acesso das comunidades ao conjunto das ações definidas pelo governo e o envolvimento de seus representantes no monitoramento daquelas que são implementadas em municípios onde existem comunidades quilombolas. 0 trabalho principal ocorre nas frentes de proteção à vida, educação em direitos humanos para as comunidades quilombolas, execução do Programa Nacional de Documentação das Trabalhadoras Rurais, garantia do registro civil de nascimento, com foco nas comunidades tradicionais. Nesse sentido, o Eixo 4 estabelece certa conexão com o Eixo 2, no que diz respeito à qualidade de vida das populações quilombolas, pois direitos e cidadania se consolidam por meio do acesso a educação, saúde, cultura e moradia de qualidade.

No estado de Mato Grosso do Sul, as escolas quilombolas estão concentradas em apenas cinco dos vinte e dois municípios que possuem comunidades quilombolas, conforme Quadro 2, são duas Escolas Estaduais, quatro Escolas Municipais e um Centro de Educação Infantil localizado na capital do estado.

Quadro 2. Escolas quilombolas no Mato Grosso do Sul. Fonte: INEP/MEC/Censo da Educação Básica - Censo Escolar SED/SUPAI/ESTATÍSTICA/Censo Escolar - Censo Escolar 2017/ Elaborado pelo autor.

\begin{tabular}{|l|l|l|l|c|}
\hline \multicolumn{1}{|c|}{ Município } & \multicolumn{1}{|c|}{ Escola } & \multicolumn{1}{c|}{ Zona } & \multicolumn{1}{c|}{ Rede } & Comunidade Quilombola \\
\hline Campo Grande & Antonio Delfino & Urbana & Estadual & \multirow{2}{*}{ Tia Eva } \\
\cline { 2 - 4 } & CEINF Tia Eva & Urbana & Municipal & \\
\hline Bonito & Águas do Miranda & Rural & Municipal & Águas do Miranda \\
\hline Figueirão & Prof. Antonio Furtado & Rural & Municipal & Santa Tereza/ Família Malaquias \\
\hline Jaraguari & Zumbi dos Palmares & Rural & Estadual & Furnas do Dionísio \\
\cline { 2 - 4 } & Dionísio Antonio - Polo & Rural & Municipal & \\
\hline Terenos & Antonio Sandim & Rural & Municipal & Comunidade dos Pretos \\
\hline
\end{tabular}

Apesar de possuir três comunidades quilombolas no município de Corumbá, não possui escola quilombola. Ainda em relação ao acesso à educação, de acordo com relatório sobre ações realizadas no ano 
de 2012 divulgado pela SEPPIR, foram instalados três telecentros nas comunidades quilombolas no estado, mas nenhum deles, em Corumbá.

A análise dos dados relativos ao monitoramento do PBQ em relação às principais ações dos quatro eixos da Agenda Social Quilombola expõe alguns avanços nas políticas públicas quilombolas no país. De acordo com Arruti (2009), esses avanços estão vinculados a mudanças de posturas e de abordagens internas ao próprio Estado, nos diferentes níveis de poder, tendo em vista o reconhecimento e o fortalecimento organizacional das comunidades quilombolas. O autor pontua quatro objetivos que devem pautar a elaboração e gestão das políticas públicas quilombolas:

\begin{abstract}
I- O incentivo aos governos estaduais e municipais na promoção do acesso de quilombolas às políticas públicas, com ênfase na regularização da posse da terra e no estímulo ao desenvolvimento sustentável em seus territórios; II- A proposição de um modelo de gestão destas políticas que preserve a igualdade de oportunidade e de tratamento dado a estas comunidades, em comparação com os demais públicos; III- O estímulo ao protagonismo dos quilombolas em todo processo de decisão, fortalecendo sua identidade cultural e política; e, finalmente, IV- a garantia dos direitos sociais e do acesso à rede de proteção social. (ARRUTI, 2009, p.79)
\end{abstract}

Tais objetivos evidenciam a necessidade de uma articulação entre os diferentes órgãos governamentais, com ações incidentes sobre as comunidades, por meio da formulação de projetos específicos de fortalecimento dos grupos discriminados, com especial atenção às mulheres e à juventude, nas mais diversas áreas: educação, saúde, mercado de trabalho, geração de renda e direitos humanos.

Quando analisamos a realidade das comunidades quilombolas pesquisadas, porém, constatamos que a consecução dos quatro objetivos para a elaboração e gestão das políticas públicas quilombolas enfrenta diversos entraves: a) pouco incentivo tanto do governo estadual quanto da prefeitura municipal de Corumbá na promoção do acesso de quilombolas às políticas públicas, bem como no processo de regularização da posse da terra; b) inexistência de um modelo de gestão das políticas que fortaleça a igualdade de oportunidades e de tratamento dado às comunidades quilombolas de Corumbá; c) falta de estímulo ao protagonismo dos quilombolas nos processo de decisão, para o fortalecimento de sua identidade cultural e política; d) nenhuma garantia de acesso aos direitos.

\title{
CONSIDERAÇÕES FINAIS
}

É importante considerar a conjuntura política brasileira no que diz respeito aos diretos das comunidades quilombolas, visto estarmos diante de um cenário que não prioriza as demandas sociais.

Apesar da homologação do Decreto no 4.887/2003 e da regulamentação do Decreto no 6.261 , que lançou o Programa Brasil Quilombola e a Agenda Social Quilombola, nota-se que os direitos das comunidades 
quilombolas enfrentam sérios riscos, posto que uma significativa porcentagem delas ainda não teve acesso às políticas públicas sobre as quais dispõem esses textos legais.

Neste trabalho, pudemos discutir os entraves impostos ao Programa Brasil Quilombola nas comunidades quilombolas do município de Corumbá, com base nas informações obtidas no Painel de Monitoramento de Ações da Agenda Social Quilombola e por meio de questionários e entrevistas realizados nas comunidades quilombolas e no Instituto da Mulher Negra do Pantanal. Foi possível constatar que a implementação das políticas públicas e a execução dos quatro Eixos da ASQ não alcançaram as comunidades quilombolas Campos Correia, Família Maria Theodora Gonçalves de Paula e Família Ozório.

As situações e realidades observadas permitem concluir que está em curso um processo de resistência das comunidades quilombolas, que buscam alternativas para a sobrevivência dos agentes sociais envolvidos, em face da exiguidade do Estado no que concerne ao acesso à terra, à falta de assistência técnica especializada, de maquinários agrícolas e de espaço para o cultivo da lavoura, bem como à precariedade da infraestrutura para o escoamento da produção. Mesmo diante das dificuldades enfrentadas, as comunidades quilombolas têm travado uma luta incessante para a conquista da cidadania e a garantia de seus direitos.

\section{REFERÊNCIAS}

ARRUTI, J. M. Políticas Públicas para Quilombos: Terra, Saúde e Educação. In: PAULA, M. HERINGER, R. (Org.) Caminhos Convergentes: Estado e Sociedade na Superação das Desigualdades Raciais no Brasil. Disponível em:

https://br.boell.org/sites/default/files/caminhos convergentes.pdf Acesso em: 17 janeiro. 2018.

ARRUTI, J. M. “Quilombos”. In: Raça: Perspectivas Antropológicas. [org. Osmundo Pinho]. ABA / Ed. Unicamp / EDUFBA. 2008.33 p.

CAPELLA, ANA C. N. Formulação de Políticas Públicas. 1. ed. Brasília: ENAP, 2018. 151p .

DELGADO, N. G.; LEITE, S. P. Políticas de Desenvolvimento Territorial no Meio Rural Brasileiro: Novas Institucionalidades e Protagonismo dos Atores. DADOS - Revista de Ciências Sociais, Rio de Janeiro, vol. 54, no 2, 2011, pp. 431 a 473 . Disponível em: http://www.scielo.br/ Acesso em: 20 janeiro. 2018.

DRAIBE, S. M. Estado de Bem-Estar, Desenvolvimento Econômico e Cidadania: algumas lições da literatura contemporânea. In: HOCHMAN, G.; ARRETCHE, M.;

FREY, K. Políticas Públicas: um Debate Conceitual e Reflexões Referentes a Prática da Análise de Políticas Públicas no Brasil. Planejamento e Políticas Públicas, n. 21, p. 211-259, 2000. http://www.ipea.gov.br

GARCIA, R. C. Subsídios para organizar avaliações da ação governamental. Planejamento e Políticas Públicas, n. 23 , junho 2001. http://www.ipea.gov.br

GOMES, Flávio dos Santos. Mocambos e Quilombos: Uma história do campesinato negro no Brasil. -1 ed. - São Paulo: Claro Enigma, 2015.

HÖFLING, E. de M. Estado e Políticas (Públicas) Sociais. Cadernos Cedes. Ano XXI, no 55, novembro/2001. Disponível em: http://www.scielo.br Acesso em: 5 de maio. 2018.

INCRA. Territórios Quilombolas: Relatório 2012. Brasília, 2012.

MARQUES, E. Políticas Públicas no Brasil. Rio de Janeiro: Fiocruz, 2007.

MONTAÑO Carlos. Terceiro Setor e Questão Social: crítica ao padrão emergente de intervenção social. São Paulo: Cortez, 2002. 
OSORIO, J. O Estado no Centro da Mundialização: a sociedade civil e o tema do poder. São Paulo: Outras Expressões, 2014.

POULANTZAS, Nicos. O Estado, o poder, o socialismo. Rio de Janeiro: Graal, 1980.

QUIJANO, A. Colonialidade do poder, eurocentrismo e América Latina. En: LANDER, E. (org). A colonialidade do saber: eurocentrismo e ciências sociais. Perspectivas latino-americanas. Colección Sur Sur, CLACSO, Ciudad Autónoma de Buenos Aires, Argentina, 2005. pp. 107- 130.

RUA, M. G. Análise de Políticas Públicas: Conceitos Básicos. In: O estudo da política: tópicos selecionados. Brasília: Paralelo 15, 1998.

SAQUET, M. A. Abordagens e concepções de território. São Paulo: Expressão Popular, 2010.

SEPPIR. Programa Brasil Quilombola. Brasília, 2004.

SOUZA, C. Políticas públicas: uma revisão da literatura. Sociologias. Porto Alegre, ano 8, jul./dez. 2006, n.16, p.20-45. Disponível em: http://www.scielo.br 